\title{
Pulsed Radiofrequency for Lumbar Facet Joint Pain: A Viable Therapeutic Option? A Retrospective Observational Study
}

\author{
Pasquale Sansone (D) - Luca G. Giaccari - Antonietta Lippiello • \\ Caterina Aurilio - Antonella Paladini - Maria Beatrice Passavanti · \\ Vincenzo Pota · Maria Caterina Pace
}

Received: May 25, 2020 / Published online: August 8, 2020

(C) The Author(s) 2020

\section{ABSTRACT}

Introduction: Low back pain (LBP) is a common problem, and facet joint pain is responsible for $15-45 \%$ of cases. Treatment is multidisciplinary, and when conservative measures are not sufficient, radiofrequency (RF) is often used. It allows the interruption of nociceptive input, producing a heat lesion in a continuous or pulsed mode.

Methods: Medical records of 60 patients who underwent pulsed RF denervation were examined. The standard procedure provided followup of pain intensity. Numerical rating scale (NRS) and Douleur Neuropathique en 4 Questions (DN4) were recorded before treatment, and 15 and 40 days, and 6 months after treatment. Oswestry Disability Index (ODI) and

Digital Features To view digital features for this article go to https://doi.org/10.6084/m9.figshare.12656810.

P. Sansone $(\varangle) \cdot$ L. G. Giaccari · C. Aurilio ·

M. B. Passavanti - V. Pota - M. C. Pace

Department of Women, Children and General and

Specialist Surgery, University of Campania "Luigi

Vanvitelli", Naples, Italy

e-mail: pasquale.sansone@unicampania.it

A. Lippiello

Department of Neurosurgery, "Santa Maria delle

Grazie Hospital", Pozzuoli, Italy

A. Paladini

Department of MESVA, "University of L'Aquila",

Aquila, Italy patient satisfaction were also recorded. Successful treatment was defined as more than a $50 \%$ reduction in the NRS scores at 6 months compared with pretreatment scores.

Results: Scores on the NRS and DN4 were statistically different over time $(p<0.05)$. Scores at 6 months were significantly decreased when compared with pretreatment scores $(p<0.05)$. ODI scores decreased during the follow-up period. No adverse effect was recorded and 57 patients (97\%) reported successful pain relief.

Conclusions: Continuous RF is the gold standard in the management of lumbar facet joint pain. Pulsed RF is a promising technique: patients with chronic LBP who had not responded to conservative care tended to improve after pulsed RF. The procedure was well tolerated in the absence of contraindications, and reliable if the nerve endings regrew.

Keywords: Facet joint pain; Pulsed radiofrequency; Radiofrequency denervation 


\section{Key Summary Points}

Low back pain (LBP) is a common problem, and facet joint pain is responsible for $15-45 \%$ of cases. Treatment is multidisciplinary, and when conservative measures are not sufficient, radiofrequency (RF) is often used.

Continuous RF is the gold standard in the management of lumbar facet joint pain. Pulsed RF is a promising technique. The aim of the study is to report a case series of patients treated with pulsed RF and to evaluate its efficacy.

We observed that mean postprocedural NRS scores were lower than those at the preprocedural stage. The DN4 values were below 4, and therefore a neuropathic pain component was not evident. ODI scores reflect functional improvement and they decreased during the follow-up period. Treated patients reported a higher level of satisfaction and no major AEs were reported.

In our opinion, pulsed RF could be considered as an alternative treatment because of its advantages over continuous $\mathrm{RF}$. We need further trials to confirm our results and to extend the real efficacy of this technique.

\section{INTRODUCTION}

Few conditions are as controversial as lumbar facet joint pain. It is a challenging condition affecting up to $15-45 \%$ of patients with chronic low back pain (LBP) [1]. The prevalence rate of lumbar facet joint pain varies widely in the literature, ranging from less than $5 \%$ to over $50 \%$ [2-5].

Chronic LBP is a complex condition, where both nociceptive and neuropathic pain mechanisms are involved. Pain arises from the activation of nociceptors secondary to alterations in intervertebral disc, lumbar facet joints, and sacroiliac joint in response to tissue injury/ inflammation and biomechanical stress (nociceptive mechanism), and from an injury or disease that directly affects nerve roots innervating the spine and lower (neuropathic mechanism) [6, 7].

Pain lasts for more than 3 months with a distribution between the segments L1-S1 [8] and a typical irradiation to the gluteal or intertrochanteric regions $[9,10]$.

The diagnosis of lumbar facet joint pain relies on the combination of symptomatology, physical examination, and confirmation by diagnostic block [11].

The treatment of facet pain is multidisciplinary, and includes analgesics (acetaminophen), non-steroidal anti-inflammatory drugs (NSAIDs), antidepressants, anticonvulsants, opioids, and topical treatments, with oral agents recommended as first-line therapy. Due to the neuropathic pain component, a multimodal treatment is often required such as physical therapy, regular exercise, and, if indicated, psychotherapy.

When conservative measures are not sufficient, radiofrequency (RF) is commonly used for patients with chronic LBP $[12,13]$. RF leads to the interruption of continuous nociceptive input producing a heat lesion that impairs or destroys the nerves. It may be continuous or pulsed. Continuous radiofrequency (CRF) generates heat around the electrode tip, coagulating the relevant nerve and blocking the transmission of nociceptive stimuli. The active mode takes up about $90 \%$ of the duty cycle. The disconnection of nerve conductivity occurs with probe temperatures between 60 and $80^{\circ} \mathrm{C}$. CRF lesions are well circumscribed, related to tissue temperature, electrode size, and procedure duration. Pulsed radiofrequency (PRF) is a relatively recent method of applying radiofrequency without raising the temperature. It is applied intermittently, taking up only $4 \%$ of the duty cycle. Temperature does not exceed $42^{\circ} \mathrm{C}$, and, probably, the therapeutic effect is a temperature-independent pathway mediated by a rapidly changing electrical field [14]. 
The effectiveness of pulsed radiofrequency denervation has not been consistently demonstrated. Nowadays, there are conflicting opinions on the use of this technique. In some studies, there is evidence of very low to moderate quality supporting the effectiveness of PRF for patients with chronic LBP [15-19]. In others, PRF stimulation seems to be an effective technique for controlling pain in joint disorders including LBP $[20,21]$.

The aim of this study is to report a case series of patients with chronic LBP treated with PRF after unsuccessful conservative treatment and to evaluate its efficacy in chronic pain management.

\section{METHODS}

A retrospective observational study was carried out collecting and examining the medical records of patients treated between October 2018 and September 2019 in the Pain Management Division, Department of Anesthesiology, "San Giuliano Hospital" (Giugliano, Italy) and in the Department of Neurosurgery, "Santa Maria delle Grazie Hospital" (Pozzuoli, Italy). The follow-up period ended in March 2020.

This study was performed in accordance with the Good Clinical Practice guidelines and the principles of the Declaration of Helsinki of 1964 and its subsequent revisions. The study was approved by the Local Ethics Committee of "San Giuliano Hospital" and "Santa Maria delle Grazie Hospital". The requirement for informed consent was waived because of the retrospective case-control nature of the study.

\section{Inclusion Criteria}

The inclusion criteria were as follows: chronic low back pain lasting for at least 3 months without satisfactory improvement in response to conservative therapies; clinical manifestations suggesting facet pain origin; pain score greater than 4 on a numerical rating scale (NRS); at least $50 \%$ temporary pain relief for at least 30 min after a selective diagnostic block using $0.5 \mathrm{ml}$ of $2 \%$ lidocaine; age of patient $\geq 18$ years.

\section{Exclusion Criteria}

The exclusion criteria were as follows: presence of radicular syndrome (sensory or motor deficits); prior lumbar surgery; prior RF treatment for LBP; mental disability or psychiatric disorder; associated major comorbidities or pregnancy.

\section{Procedure}

For each patient, we collected medical history, complete general and neurological assessment, and lumbar spine magnetic resonance imaging (MRI). The RF treatment was performed by the same physician.

Before starting the procedure, patients underwent a single medial branch block (MBB), aseptically injecting $0.5 \mathrm{ml}$ of $2 \%$ lidocaine. This was performed in the pain trigger point and no sedation was performed. Only patients experiencing at least a $50 \%$ reduction of LBP on the NRS measured $30 \mathrm{~min}$ after the injection were eligible to receive PRF.

Treatment was performed with patients in a prone position using RF generator with C-arm fluoroscopy guidance. As shown in Fig. 1, a 23-gauge cannula was inserted under fluoroscopy, perpendicular to the nerves at the angle between the superior articular process and the transverse one for L1-4 levels. The needle was directly directed at the dorsal ramus towards the junction of the superior articular process and the top border of the sacral crest for the L5 level. To confirm the right placement, an arthrogram of the lumbar facet joint (LFJ) was obtained by injecting $0.3 \mathrm{ml}$ of radiopaque contrast. Before treatment, motor stimulation up to $1 \mathrm{~V}$ was applied to detect the correct placement of the electrode. After local anesthetic injection ( $2 \mathrm{ml}$ bupivacaine), patients received PRF: an electrode was connected to the cannula, and the LFJ was stimulated. PRF treatment was administrated with the following characteristics: (1) electrode tip temperature not exceeding $42{ }^{\circ} \mathrm{C}$; (2) duration of $240 \mathrm{~s}$; (3) voltage of $45 \mathrm{~V}$; (4) pulse rate of $5 \mathrm{~Hz}$; and (5) pulse width of $5 \mathrm{~ms}$. 
After the procedure, the patients were monitored for $2 \mathrm{~h}$ and were discharged after ensuring that there were no complications. Eventual adverse events (AEs) during the procedures were recorded.

Patients were regularly followed up until 6 months after PRF treatment. Pain intensity was assessed using NRS, with values between 0 ("no pain") and 10 ("the most intense pain imaginable"), and Douleur Neuropathique en 4 Questions (DN4), calculated as the sum of ten items with cut-off value for the diagnosis of neuropathic pain at $4 / 10$.

The scores were measured before treatment, and 15 and 40 days, and 6 months after treatment. Successful treatment was defined as more than $50 \%$ pain reduction measured with NRS score at 6 months compared with pretreatment score.

If NRS score was greater than 4, a conservative treatment (nonsteroidal anti-inflammatory drugs) was expected as standard. No other

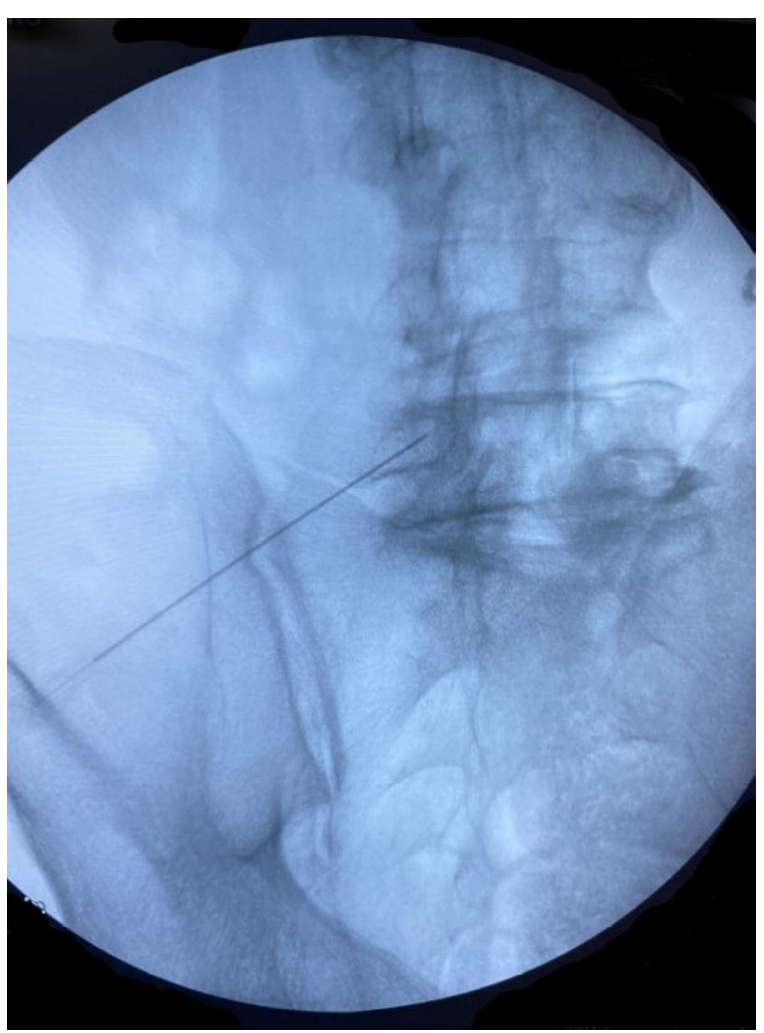

Fig. 1 Fluoroscopic-guided cannula insertion interventional therapy was performed during the follow-up period.

The Oswestry Disability Index (ODI) was evaluated to determine the degree to which pain interferes with the performance of daily activities before and after radiofrequency treatment.

Patient satisfaction was recorded using a four-point verbal rating scale $(0=$ "very dissatisfied", $\quad 1=$ "dissatisfied", 2 = "neutral", $3=$ "satisfied", 4 = "very satisfied").

\section{Statistical Analysis}

Data were analyzed using a standard computer program (Excel, 2016). Results were reported as mean \pm standard deviation (SD). We tested the consistency of our data using Chi-square test and 95\% confidence level.

Subjects were measured at a fixed number of time points, then the data were balanced. The research hypothesis was that the mean pain scores were different over time. To test for a significant difference in means over time, a repeated-measures ANOVA was used. The level of statistical significance was $p<0.01$.

\section{RESULTS}

The medical records of 74 patients suffering from LBP were examined. Fourteen patients were excluded from the study as the pain in the test block was not relieved with local anesthesia. Finally, 60 patients were included in our retrospective study.

Mean age was $62.7 \pm 15.1$ years (range, 25-85), and there were 20 males and 40 females;

Table 1 Demographic characteristics

\begin{tabular}{ll}
\hline Age (years) & $62.7 \pm 15.1$ \\
Height $(\mathrm{cm})$ & $169 \pm 70.38$ \\
Weight $(\mathrm{kg})$ & $79.41 \pm 11.26$ \\
Gender $(\mathrm{F} / \mathrm{M})$ & $40 / 20$ \\
Manual handling of loads $(\%)$ & 43 \\
\hline
\end{tabular}


Table 2 Distribution of RF levels $(n)$

\begin{tabular}{lcc}
\hline Levels of ablation & Procedure $(n)$ & Levels $(n)$ \\
\hline Right $\mathrm{L}_{2-5}$ & 4 & 16 \\
Left $\mathrm{L}_{2-5}$ & 3 & 12 \\
Bilateral $\mathrm{L}_{2-5}$ & 9 & 72 \\
Right $\mathrm{L}_{4-5}$ & 7 & 14 \\
Left $\mathrm{L}_{4-5}$ & 8 & 16 \\
Bilateral $\mathrm{L}_{4-5}$ & 11 & 44 \\
Right $\mathrm{L}_{3-5}$ & 6 & 18 \\
Left $\mathrm{L}_{3-5}$ & 5 & 15 \\
Bilateral $\mathrm{L}_{3-5}$ & 7 & 42 \\
Total & 60 & 249 \\
\hline
\end{tabular}

$43 \%$ of the patients were employed, or had been, in a manual handling job. Manual handling of loads (MHL) is defined as "the use of the human body to lift, lower, fill, empty, or carry loads" [22]. The main characteristics of the patients enrolled in this study are shown in Table 1.

The distribution of RF levels is presented in Table 2.

NRS and DN4 values in the preoperative period and after 15 days, 40 days and 6 months are shown in Fig. 2 and Table 3. Initially, the patients presented a mean NRS score of $9.62 \pm 0.64$, whereas 15 and 40 days after radiofrequency treatment we observed a significant decrease $(p<0.01)$ in pain intensity, with an average NRS score of $1.98 \pm 1.04$ and $2.09 \pm 1.12$. This difference persisted 6 months after treatment (mean NRS $=2.18 \pm 1.85$ ).

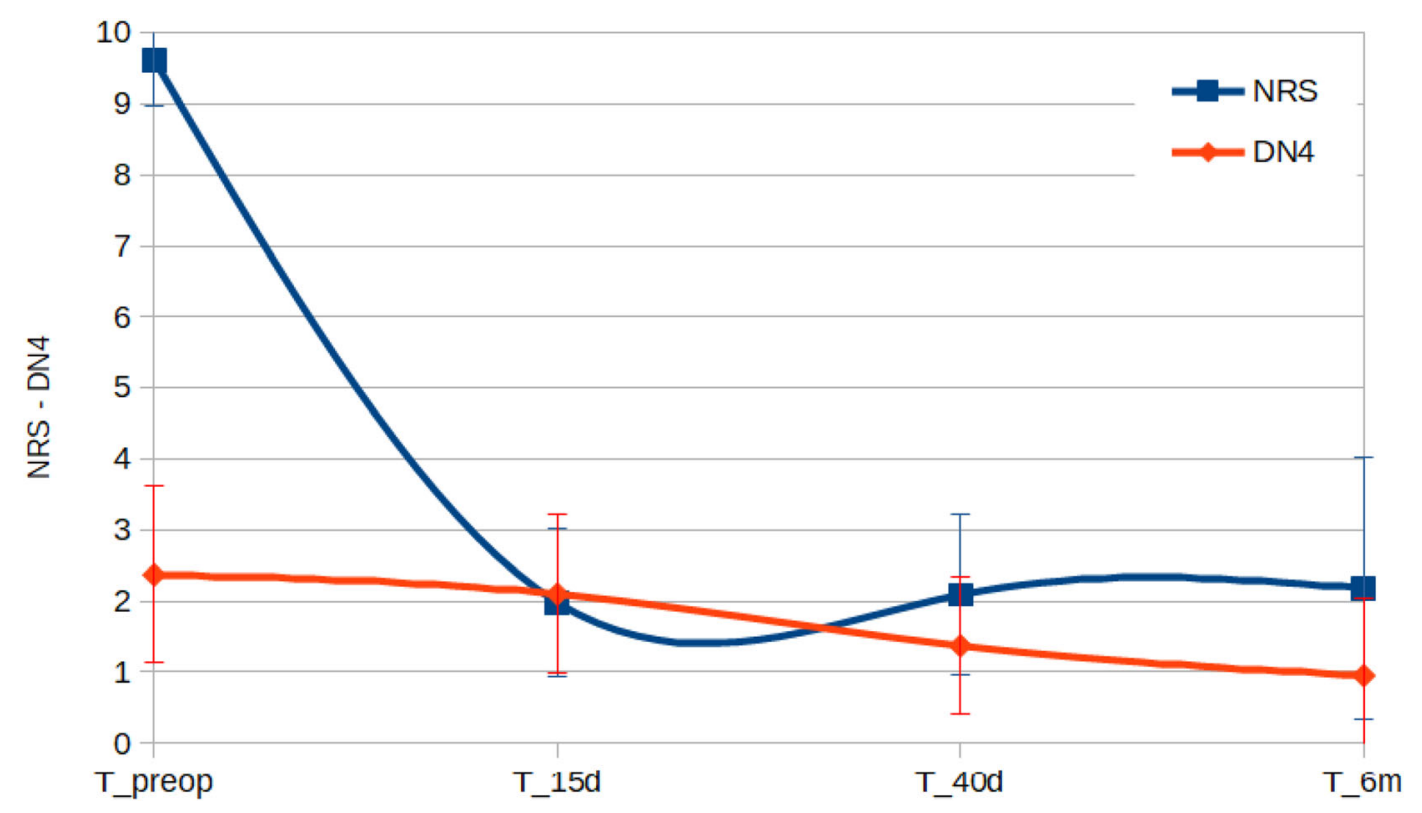

Fig. 2 NRS and DN4 at preoperative visit and at 15 days, 40 days, and 6 months

Table 3 NRS and DN4 at preoperative visit and at 15 days, 40 days, and 6 months

\begin{tabular}{llllll}
\hline & T0 & T1 & T2 & T3 & P \\
\hline NRS & $9.62 \pm 0.64$ & $1.98 \pm 1.04$ & $2.09 \pm 1.12$ & $2.18 \pm 1.85$ & $<0.01^{*}$ \\
DN4 & $2.37 \pm 1.24$ & $2.01 \pm 1.11$ & $1.37 \pm 0.97$ & $0.95 \pm 1.10$ & $<0.01^{*}$ \\
\hline
\end{tabular}

${ }^{*}$ Statistically significant 
DN4 value was $2.37 \pm 1.24$ at preoperative visit; values were lower after 15 days $(\mathrm{T} 1=2.01 \pm 1.11), 40$ days $(\mathrm{T} 2=1.37 \pm 0.97)$ and 6 months $(\mathrm{T} 3=0.95 \pm 1.10)$.

The operation was repeated for one patient (1.7\%) after 15 days, for 10 patients (16.7\%) after 40 days, and for 21 patients (35\%) at the sixth month.

Bilateral medial branch PRF neurolysis was performed on 27 patients. Medial branch PRF neurolysis was performed from the right side in 17 patients and from the left side in 16 patients. Medial branch PRF neurolysis was performed for a total of 249 levels.

The 60 patients included in the study had a basal ODI score of $53.28 \%$, reflecting severe disability. After 15 and 40 days, the mean ODI score was $13.18 \%$ and $15.26 \%$, which differed significantly from the pretreatment score $(p<0.01)$. Moreover, this difference relative to the pretreatment score was maintained at sixth month after treatment (mean ODI score $=$ $19.18 \%)$. Evolution of the ODI score is shown in Fig. 3.

When patient satisfaction was measured at the sixth month using a five-point verbal rating scale, $35 \%$ of patients were satisfied and $43.3 \%$ were very satisfied. As shown in Table 4, 78.3\%
Table 4 Patient satisfaction

\begin{tabular}{lc}
\hline Satisfaction level & No. (\%) \\
\hline Very dissatisfied & $0(0)$ \\
Dissatisfied & $8(13.3)$ \\
Neutral & $5(8.3)$ \\
Satisfied & $21(35)$ \\
Very satisfied & $26(43.3)$ \\
\hline
\end{tabular}

of patients who underwent RF achieved a significant level of satisfaction.

No AEs were observed after RF treatment, although a few patients reported mild pain at the puncture site in the days following treatment. This discomfort was resolved spontaneously without any need for further treatment.

\section{DISCUSSION}

Low back pain is a common problem, and facet joint pain is responsible for $15-45 \%$ of those patients with chronic LBP [1].

Currently, the "gold standard" for treating facet joint pain is radiofrequency [23]. RF is commonly used for patients with chronic LBP

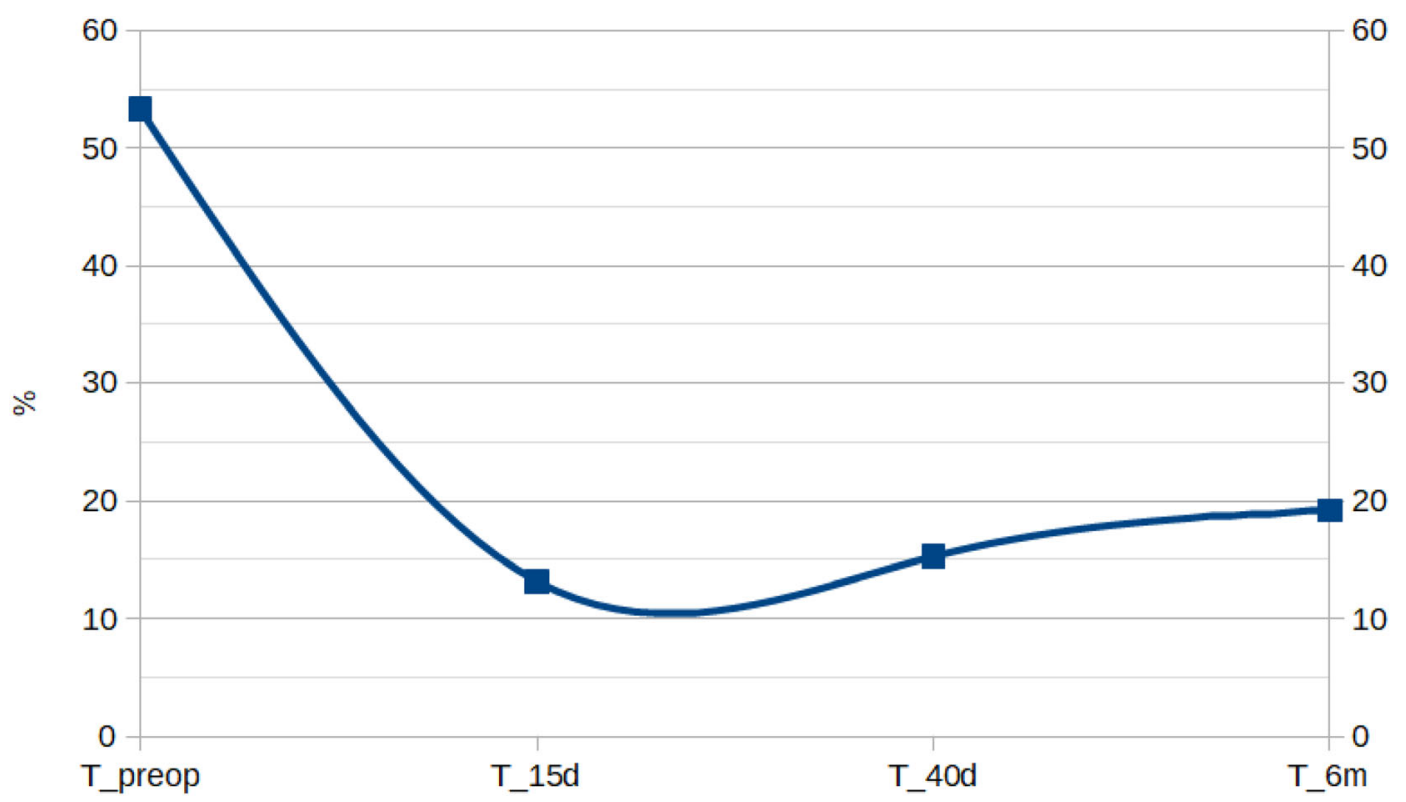

Fig. 3 Preoperative ODI score and at 15 days, 40 days, and 6 months 
after conservative management failure $[12,13]$. The strongest indicator for lumbar facet pain is pain reduction after anesthetic blocks of medial branches of the rami dorsales that innervate the facet joints [23]. Because false-positive and, possibly, false-negative results may occur, the results must be interpreted carefully [24]. In our study, 14 patients were excluded from the study, as they did not respond enough to the diagnostic block. We only included patients who presented at least $50 \%$ temporary pain relief after MBB [23]. In our opinion, it is important to have a correct diagnostic block to confirm imaging data and clinical suspicion, even if this is not always easy to perform in clinical practice.

According to recent results, CRF seems to be more effective than PRF [15-19]. CRF has been used for approximately 40 years for various medical conditions. It ablates the nerves or tissues by increasing the temperature around the RF needle tip [12]. However, CRF causes diffuse tissue damage due to destructive temperatures [12]. To overcome its destructive adverse effect, PRF was developed [25]. The tissue temperature reaches a maximum of $42{ }^{\circ} \mathrm{C}$, which prevents the unwanted adverse effect of irreversible tissue damage [13-15].

In our study, we observed that mean postprocedural NRS scores were lower than those at the preprocedural stage. The NRS values of all patients were below 4 at the sixth month. However, these rates were reached by the repetition of the procedure. The operation was repeated for a patient after 15 days, for ten patients after 40 days, and for 21 patients after 6 months. PRF uses less energy and lower temperature than CRF. This suggests that PRF does not form lesions fully and thus the duration of the effectiveness of the PRF seems to be lower than that of the CRF [20].

The DN4 values were below 4, therefore a neuropathic pain component was not evident among screened patients. The prevalence of neuropathic pain in LBP is approximately 5\% [6]. It is associated with increased likelihood and severity of medical comorbidities and reduced quality of life when compared with LBP without a neuropathic component [6].
ODI scores reflect functional improvement and they decreased during the follow-up period. The mean disability level observed in the pretreatment visit with the help of the ODI questionnaire was $53.28 \%$, which represents severe disability. This is in accordance with previous studies, which present moderate-to-severe disability showing the extent to which chronic low back pain patients cannot perform daily activities normally [26]. We reported minimal disability (ODI mean score $15.87 \%$ ) after the intervention. This result indicated that PRF treatment was effective regarding pain relief.

Treated patients reported a higher level of satisfaction $(78.3 \%$ satisfied or very satisfied). No major AEs were reported and only a few patients reported mild pain at the puncture site in the days following the treatment. The application of PRF to medial branches of the dorsal rami in patients with chronic facet joint arthropathy provided temporary pain relief with no complications, making it an attractive treatment option [27]. The duration of effect of the procedure and a lack of complications correlate with the results of other studies $[25,28]$.

Some possible predictive factors for successful outcomes of PRF treatment in patients with low back pain were recently found [29], and could explain the positive outcome in our study sample. PRF showed better results in patients aged at least 55 years old, with limited disability and after a positive diagnostic nerve block. A combination of all these factors has a positive predictive value.

According to the available literature, PRF has demonstrated a high-security profile and could be used as an alternative to CRF, avoiding the side effects due to continuous administration of current [20, 21]. Furthermore, one recent study showed that $80 \%$ of patients undergoing PRF treatment rejected spinal surgery in the short term and $76 \%$ in the long term [30].

\section{Limitations}

The main limitation of our study is its observational retrospective nature. Observational trials have a higher chance of overestimating treatment effects. Given the recent results, we cannot exclude that the results from our study 
were due to the natural history or other nonspecific factors including the placebo effect. Second, the study was conducted without a control group. Third, the sample is limited to 60 patients. Finally, another limitation was the risk of false-positive blocks. The incidence of false positives with the use of single blocks is between 22 and 47\%. However, according to a recent consensus, the criteria for a positive response using a single $\mathrm{MBB}$ was a reported 50\% or more pain relief on the occasion of block.

\section{CONCLUSIONS}

From the available evidence, CRF is used in the management of lumbar facet joint pain. PRF is a promising technique: it is effective for a short period in the medial branch block performed due to lumbar facet joint pain, but its effectivity is weaker compared to CRF [15-19].

In our opinion, PRF could be considered as an alternative treatment because of its advantages over CRF. In fact, PRF is safer and reduces the risk of tissue damage. Patients also reported a very high level of satisfaction, demonstrating that a less-invasive approach like PRF could result in a better option for the patient.

Predictive factors for successful outcome of PRF in patients with LBP have to be better explored, as these can help in selecting the most appropriate therapeutic technique.

MBB is the prognostic screening test of choice before lumbar facet RFA, but studies should be performed to increase its sensitivity for identifying denervation candidates.

Finally, the PRF mechanism of action is not completely understood, and there are not enough data in the literature about the efficacy of PRF in the treatment of chronic facet joint pain.

We need further trials to confirm ours results and to extend the real efficacy of this technique.

\section{ACKNOWLEDGEMENTS}

Funding. No funding or sponsorship was received for this study or publication of this article.
Authorship. All named authors meet the International Committee of Medical Journal Editors (ICMJE) criteria for authorship for this article, take responsibility for the integrity of the work as a whole, and have given their approval for this version to be published.

Authorship Contributions. Pasquale Sansone helped design the study, conduct the study, analyze the data, and write the manuscript; Luca Gregorio Giaccari helped design the study, analyze the data, and write the manuscript; Antonietta Lippiello helped design the study, conduct the study, and analyze the data; Caterina Aurilio helped design the study and analyze the data; Antonella Paladini helped design the study and analyze the data; Maria Beatrice Passavanti helped design the study and analyze the data; Vincenzo Pota helped design the study and analyze the data; Maria Caterina Pace helped design the study and analyze the data.

Disclosures. Pasquale Sansone, Luca G. Giaccari, Antonietta Lippiello, Caterina Aurilio, Maria Beatrice Passavanti, Vincenzo Pota and Maria Caterina Pace have nothing to disclose. Antonella Paladini is a member of the journal's Editorial Board.

Compliance with Ethics Guidelines. This study was performed in accordance with the Good Clinical Practice guidelines and the principles of the Declaration of Helsinki of 1964 and its subsequent revisions. The study was approved by the Local Ethics Committee of "San Giuliano Hospital" and "Santa Maria delle Grazie Hospital". The requirement for informed consent was waived because of the retrospective case-control nature of the study.

Data Availability. The datasets generated during and/or analyzed during the current study are available from the corresponding author on reasonable request.

Open Access. This article is licensed under a Creative Commons Attribution-NonCommercial 4.0 International License, which permits any non-commercial use, sharing, adaptation, 
distribution and reproduction in any medium or format, as long as you give appropriate credit to the original author(s) and the source, provide a link to the Creative Commons licence, and indicate if changes were made. The images or other third party material in this article are included in the article's Creative Commons licence, unless indicated otherwise in a credit line to the material. If material is not included in the article's Creative Commons licence and your intended use is not permitted by statutory regulation or exceeds the permitted use, you will need to obtain permission directly from the copyright holder. To view a copy of this licence, visit http://creativecommons.org/licenses/bync/4.0/.

\section{REFERENCES}

1. Schwarzer AC, Wang SC, Bogduk N, McNaught PJ, Laurent R. Prevalence and clinical features of lumbar zygapophysial joint pain: a study in an Australian population with chronic low back pain. Ann Rheum Dis. 1995;54:100-6.

2. Falco FJE, Manchikanti L, Datta S, et al. An update of the systematic assessment of the diagnostic accuracy of lumbar facet joint nerve blocks. Pain Physician. 2012;15:E869-907.

3. Long DM, BenDebba M, Torgerson WS, et al. Persistent back pain and sciatica in the United States: patient characteristics. J Spinal Disord. 1996;9: $40-58$.

4. Ko S, Vaccaro AR, Lee $\mathrm{S}$, et al. The prevalence of lumbar spine facet joint osteoarthritis and its association with low back pain in selected Korean populations. Clin Orthop Surg. 2014;6:385-91.

5. Kalichman L, Li L, Kim DH, et al. Facet joint osteoarthritis and low back pain in the communitybased population. Spine. 2008;33:2560-5.

6. Baron R, Binder A, Attal N, Casale R, Dickenson AH, Treede R-D. Neuropathic low back pain in clinical practice. Eur J Pain Lond Engl. 2016;20:861-73.

7. Aurilio C, Pota V, Pace MC, Passavanti MB, Barbarisi M. Ionic channels and neuropathic pain: physiopathology and applications. J Cell Physiol. 2008;215:8-14.
8. Manchikanti L, Singh V. Review of chronic low back pain of facet joint origin. Pain Physician. 2002;5:83-101.

9. Beresford ZM, Kendall RW, Willick SE. Lumbar facet syndromes. Curr Sports Med Rep. 2010;9:50-6.

10. Mooney V, Robertson J. The facet syndrome. Clin Orthop Relat Res. 1976;115:149-56.

11. Datta S, Lee M, Falco FJE, Bryce DA, Hayek SM. Systematic assessment of diagnostic accuracy and therapeutic utility of lumbar facet joint interventions. Pain Physician. 2009;12:437-60.

12. van Wijk RM, Geurts JW, Wynne HJ. Long-lasting analgesic effect of radiofrequency treatment of the lumbosacral dorsal root ganglion. J Neurosurg. 2001;94(2 Suppl):227-31.

13. van Kleef $M$, Vanelderen $\mathrm{P}$, Cohen SP, Lataster A, Van Zundert J, Mekhail N. Pain originating from the lumbar facet joints. Pain Pract. 2010;10(5): 459-69.

14. Byrd D, Mackey S. Pulsed radiofrequency for chronic pain. Curr Pain Headache Rep. 2008;12(1): $37-41$.

15. Juch JNS, Maas ET, Ostelo RWJG, et al. Effect of radiofrequency denervation on pain intensity among patients with chronic low back pain: the mint randomized clinical trials. JAMA. 2017;318(1): 68-81.

16. Facchini G, Spinnato P, Guglielmi G, Albisinni U, Bazzocchi A. A comprehensive review of pulsed radiofrequency in the treatment of pain associated with different spinal conditions. $\mathrm{Br} \mathrm{J}$ Radiol. 2017;90(1073):20150406.

17. Çetin A, Yektaş A. Evaluation of the short- and long-term effectiveness of pulsed radiofrequency and conventional radiofrequency performed for medial branch block in patients with lumbar facet joint pain. Pain Res Manag. 2018;2018:7492753.

18. Contreras Lopez WO, Navarro PA, Vargas MD, Alape E, Camacho Lopez PA. Pulsed radiofrequency versus continuous radiofrequency for facet joint low back pain: a systematic review. World Neurosurg. 2019;122:390-6.

19. Shih CL, Shen PC, Lu CC, et al. A comparison of efficacy among different radiofrequency ablation techniques for the treatment of lumbar facet joint and sacroiliac joint pain: a systematic review and meta-analysis. Clin Neurol Neurosurg. 2020;195: 105854.

20. Boudier-Revéret M, Thu AC, Hsiao MY, Shyu SG, Chang MC. The effectiveness of pulsed 
radiofrequency on joint pain: a narrative review. Pain Pract. 2020;20(4):412-21.

21. Napoli A, Alfieri G, Scipione R, Andrani F, Leonardi A, Catalano C. Pulsed radiofrequency for low-back pain and sciatica. Expert Rev Med Devices. 2020;17(2):83-6.

22. Zin C, Hight R, Jackson K, Patel J, Wagner F. Ergonomic guidelines for manual material handling. DHHS Publication. No. 2007-131. National Institute for Occupational Safety and Health. Retrieved October 7, 2008.

23. Cohen SP, Bhaskar A, Bhatia A, et al. Consensus practice guidelines on interventions for lumbar facet joint pain from a multispecialty, international working group. Reg Anesth Pain Med. 2020;45: 424-67.

24. Cohen SP, Hurley RW, Christo PJ, Winkley J, Mohiuddin MM, Stojanovic MP. Clinical predictors of success and failure for lumbar facet radiofrequency enervation. Clin J Pain. 2007;23(1):45-52.

25. Sluijter ME, Cosman ER, Rittman WB, Van Kleef M. The effects of pulsed radiofrequency fields applied to the dorsal root ganglion: a preliminary report. Pain Clin. 1998;11:109-17.

26. Grotle M, Foster NE, Dunn KM, Croft P. Are prognostic indicators for poor outcome different for acute and chronic low back pain consulters in primary care? Pain. 2010;151(3):790-7.

27. Vanneste T, Van Lantschoot A, Van Boxem K, Van Zundert J. Pulsed radiofrequency in chronic pain. Curr Opin Anaesthesiol. 2017;30(5):577-82.

28. Mikeladze G, Espinal R, Finnegan R, Routon J, Martin D. Pulsed radiofrequency application in treatment of chronic zygapophyseal joint pain. Spine J. 2003;3(5):360-2.

29. Van Boxem K, de Meij N, Patijn J, et al. Predictive factors for successful outcome of pulsed radiofrequency treatment in patients with intractable lumbosacral radicular pain. Pain Med. 2016;17: 1233-40.

30. Trinidad JM, Carnota AI, Failde I, Torres LM. Radiofrequency for the treatment of lumbar radicular pain: impact on surgical indications. Pain Res Treat. 2015;2015:392856. 